\title{
Weather, Fertilizer, Previous Year Yield, and Fertilizer Levels Affect Ensuing Year Fertilizer Response of Wheat
}

Kefyalew Girma, Starr L. Holtz, Daryl B. Arnall, Lisa M. Fultz, Travis L. Hanks, Kyle D. Lawles, Clinton J. Mack, Kevin W. Owen, Stewart D. Reed, Jesus Santillano, Olga Walsh, Michael J. White, and W.R. Raun*

\section{ABSTRACT}

Response to fertilizer is a function of several factors including weather, soil condition, previous year yield level, and the actual amount of fertilizer applied. The main objectives of this paper were to evaluate if cumulative precipitation (PPT), growing degree days (GDD), soil moisture (SM) and fertilizer can explain variability in long-term grain yield and fertilizer response index (RI); to assess if demand for $\mathbf{N}$ fertilizer is greater the ensuing year given low or high yield levels in the previous year; and to evaluate if rainfall distribution coupled with the previous year grain yield level and RI of winter wheat (Triticum aestivum $L$.) improves the predictability of ensuing year RI. Data from two long-term experiments located at Stillwater and Lahoma, OK were used in this report. The experimental design was a randomized complete block with four replications. Twelve (Stillwater) and thirteen (Lahoma) treatments that consisted of annual application of $\mathbf{N}, \mathbf{P}$ and $\mathbf{K}$ inorganic fertilizers were included although selected treatments were used to address the objectives. Soil moisture at $75 \mathrm{~cm}$ depth was a better predictor of both grain yield $\left(R^{2}=0.35\right)$ and $R I$ $\left(R^{2}=0.66\right)$ at Stillwater while SM at the $60 \mathrm{~cm}$ depth was significantly correlated to grain yield $\left(R^{2}=0.39\right)$ at Lahoma. For years where the previous year yield was low, the ensuing year had a low RI while in many years where the previous yield was high; the ensuing year had a high RI in both experiments. The practical significance of these findings is that producers could theoretically adjust preplant or inseason topdress $\mathbf{N}$ fertilizer rates by considering the previous year yield level and the degree of response to $N$.

\begin{abstract}
A NUMBER OF APPROACHES have been used to recommend $\mathrm{N}$ fertilizer, including the yield goal approach (Chang et al., 2004; Black and Bauer, 1988; Dahnke et al., 1988) and soil test based recommendations (Blackmer et al., 1997). Many methods fail to address temporal variability that alters nutrient demand and crop response in a given year. Fluctuations in crop yields are not always a result of poor producer management. Temporal yield variability is a result of differences in temperature and PPT (Johnson and Raun, 2003), which determine biological availability of nutrients and ease of crop uptake. This suggests that the nutrient use efficiency of winter wheat is partially a function of weather and the availability of nutrients. Weather is unpredictable (Lobell et al., 2004) from year to year and within years, constituting the essence of temporal variability. Flowers et al. (2004) found that for wheat grain yield, $\mathrm{N}$ fertilizer application timing
\end{abstract}

Dep. of Plant and Soil Sciences, Oklahoma State Univ., Stillwater, OK 74078. Contribution from the Oklahoma Agric. Exp. Stn. Received 17 Jan. 2007. *Corresponding author (bill.raun@okstate.edu).

Published in Agron. J. 99:1607-1614 (2007).

Production Agriculture

doi:10.2134/agronj2007.0030

(c) American Society of Agronomy

677 S. Segoe Rd., Madison, WI 53711 USA during the growing season accounted more for improvement of nitrogen use efficiency (NUE) than managing spatial variability. Optimal $\mathrm{N}$ rates were reduced $50 \%$ with in-season $\mathrm{N}$ fertilizer application and were reduced another $20 \%$ when temporal variability was considered.

Contrasting results were found by Lobell et al. (2004) who reported that soil variability is approximately two to three times greater than variability in weather, in the Yaqui Valley, in northwest Mexico, where spring wheat is grown under irrigation. The apparent contradiction between the Flowers et al. (2004) and Lobell et al. (2004) experiments can be explained by a reduction of temporal variability, which is largely related to yearto-year variability in timing and amounts of PPT, since Lobell's work was conducted under irrigation and in an area of consistent growing season temporal fluctuations. In later research, Lobell et al. (2005) concluded that variability of irrigated spring wheat from field to field was dependent on management practices (e.g., timing of irrigation, $\mathrm{N}$ fertilizer application) but the magnitude of their importance depended on year-to-year changes in environmental conditions.

Weather strongly influences soil biological activity and grain yield of wheat. Challinor et al. (2005) reported that periods of high temperature near flowering can reduce yield of annual crops. Phillips et al. (1996) found that increasing $\mathrm{CO}_{2}$ levels from 350 to $625 \mathrm{mg} \mathrm{kg}^{-1}$ resulted in a $17 \%$ yield increase for corn (Zea mays L.) and $27 \%$ for soybean [Glycine $\max$ (L.) Merr.]. In Australia, studies found that a $15 \%$ reduction in PPT can be compensated for by a $2{ }^{\circ} \mathrm{C}$ increase in temperature and $50 \%$ higher $\mathrm{CO}_{2}$ concentrations (Asseng et al., 2004; Ludwig and Asseng, 2006). Sayre et al. (1997) reported that high temperatures can shorten growth cycles. With shortened growth cycles and a reduced water supply, it is likely that crop production will be reduced (Turner, 1997). In rice (Oryza sativa L.), grain yield declined by $10 \%$ for each $1{ }^{\circ} \mathrm{C}$ increase in the minimum temperature during the dry season, while maximum temperatures had limited impact on crop yields. This supports reports of decreased rice yields from increased nighttime temperatures (Peng et al., 2004).

Growing degree days have been used to predict flowering dates, harvest maturity, and the duration between developmental stages (Bonhomme, 2000; Lu et al., 2001). Growing degree days are computed by subtracting a base temperature of $4.4^{\circ} \mathrm{C}$ from the average of the maximum and minimum temperatures for the day (McMaster and Wilhelm, 1997) for wheat. The base temperature varies depending on the crop. Growing

Abbreviations: GDD, growing degree days; NUE, nitrogen use efficiency; PPT, precipitation; RI, response index; SM, soil moisture. 
degree days have been used as a factor in prediction models of in-season yield estimates. Derby et al. (2004) attempted to predict corn grain yield based on the current year's cumulative GDD from 1 May to 10 July and total available $\mathrm{N}$ (soil $\mathrm{N}$ plus applied fertilizer $\mathrm{N}$ ). Their results showed that predicted yield of corn on 10 July was highly correlated to observed yields when using GDD as an exploratory variable $\left(r^{2}=0.80\right)$.

Previous studies have shown that high rates of fertilizer $\mathrm{N}$ on a long-term basis can affect subsequent N response (Motavalli et al., 1992; Jenkinson, 1991; Odell et al., 1983). Further it has been documented that higher rates of inorganic- $\mathrm{N}$ fertilization hasten mineralization (El-Harris et al., 1983). A Canadian study conducted with continuous wheat showed that high rates of $\mathrm{N}$ resulted in increased mineralizable forms of nitrogen (Janzen, 1987). They attributed this to increased biomass production and subsequent return to the soil coupled with greater microbial activity.

Based on this premise, researchers developed a fertilizer RI as an indicator of responsiveness of the crop to applied fertilizer (Johnson et al., 2000). The index gauges the actual winter wheat crop response to applied $\mathrm{N}$ and can be used to predict current year $\mathrm{N}$ requirements. Mullen et al. (2003) indicated that the index is suited for in-season correction of $\mathrm{N}$ requirements of winter wheat. Furthermore, evaluation of the RI over several years could help producers refine preplant $\mathrm{N}$ rates. In this study, we evaluated the possibility of using previous year RI ( $\left.\mathrm{RI}_{\text {previous }}\right)$ on ensuing year RI ( $\mathrm{RI}_{\text {ensuing }}$ ) using several years of data. The index can have a range of values depending on the yield of the check and fertilized plots. Theoretically, RI values greater than 1.1 show a high chance of crop response to applied fertilizer $\mathrm{N}$ (Raun et al., 2005). However, values exceeding 4.0 are practically beyond maximum achievable grain yield and not common for seasons where growing conditions are closer to normal. Mullen et al. (2003) further suggested that when RI is low it is likely that $\mathrm{N}$ sources other than fertilizer (i.e., mineralization and atmospheric deposition via rainfall) were available in the soil, thus the crop would be unlikely to respond to added fertilizer.

The objectives of this paper were to: (i) evaluate if cumulative PPT, GDD, and SM can explain variability in long-term grain yield and RI in winter wheat; (ii) assess if demand for $\mathrm{N}$ fertilizer is greater the ensuing year given low or high yield levels in the previous year; (iii) determine if rainfall distribution coupled with previous year grain yield level and RI improves the predictability of ensuing year RI.

\section{MATERIALS AND METHODS}

\section{Description of the Long-term Experiments}

Data from two long-term experiments, namely, Exp. 222 and 502 were used in this report. Experiments 222 and 502 were established in 1969 and 1970, respectively, under conventional tillage. Exp. 222 is located at the Agronomy Research Station in Stillwater, OK $\left(36^{\circ} 7^{\prime} 12.0^{\prime \prime} \mathrm{N}, 97^{\circ} 5^{\prime} 24.0^{\prime \prime} \mathrm{W}\right.$ at altitude of 272 masl) on a well drained, very deep and very slowly permeable Kirkland silt loam (fine, mixed, thermic Udertic Paleustoll). Exp. 502 is located at the North Central Research Station in Lahoma, OK $\left(36^{\circ} 25^{\prime} 12.0^{\prime \prime} \mathrm{N}, 97^{\circ} 52^{\prime} 12^{\prime \prime} \mathrm{W}\right.$ at altitude of 396 masl) on a well drained, deep and moderately permeable Grant silt loam (fine-silty, mixed, thermic Udic Argiustoll) soil. The average annual PPT at Stillwater and Lahoma is approximately $80 \mathrm{~cm}$.

The experimental design was a randomized complete block with four replications in both experiments. There were 12 and 13 treatments that comprised application of different rates of N, P, and K fertilizers included in Exp. 222 and 502, respectively (Table 1 ). Nitrogen, $\mathrm{P}$, and $\mathrm{K}$ were applied as ammonium nitrate $(34 \% \mathrm{~N})$, triple super phosphate $(20 \% \mathrm{P})$, and potassium chloride $(53 \% \mathrm{~K})$, respectively, in both experiments. Plots are permanent from year to year and received fixed rates of $\mathrm{N}, \mathrm{P}$, and $\mathrm{K}$ every year. Individual plots at Stillwater are $6.1 \mathrm{~m}$ wide and $18.3 \mathrm{long}$, and at Lahoma are $4.9 \mathrm{~m}$ wide and $18.3 \mathrm{~m}$ long.

Experimental plots were conventionally tilled every year in the summer approximately to a 15 -cm depth using a disk plow. Plots were then harrowed before fertilization using a spike tooth harrow every year. Winter wheat was planted for 35 (Stillwater) and 34 (Lahoma) continuous years in 25.4-cmwide rows at seeding rates of $67 \mathrm{~kg} \mathrm{ha}^{-1}$. In some years, the seeding rate was increased to $110 \mathrm{~kg} \mathrm{ha}^{-1}$ in anticipation of poor germination and emergence due to unfavorable soil moisture conditions at seeding. Since 1992, winter wheat has been planted in 19.1-cm rows at Stillwater. At this location, the variety 'Scout 66' was planted from 1968 to 1973, 'Triumph 64' from 1974 to 1977, 'Osage' from 1978 to 1980, 'TAM W-101' from 1981 to 1991 , 'Karl' from 1992 to 1994 , 'Tonkawa' from 1995 to 1998, and 'Custer' since 1999. At Lahoma, the variety 'Nicoma' was planted from 1971 to 1974, 'Triumph 64' from 1975 to 1976 and 1978 , 'Osage' in 1977 and 1979, 'TAM W-101' from 1980 to 1991, 'Karl' from 1993 to 1994, 'Tonkawa' from 1995 to 1998, and 'Custer' from 1999 to present. In both experiments, preplant fertilizer was broadcast and incorpo-

Table 1. Grain yield and response index (RI) for treatments averaged over all years for Exp. 222 and 502, at Stillwater and Lahoma, OK, respectively. $\dagger$

\begin{tabular}{|c|c|c|c|c|c|}
\hline \multicolumn{3}{|c|}{ Exp. 222} & \multicolumn{3}{|c|}{ Exp. 502} \\
\hline $\mathbf{N}-\mathbf{P}-\mathbf{K}$ & Grain yield & $\mathbf{R I}+$ & $\mathbf{N}-\mathbf{P}-\mathbf{K}$ & Grain yield & RI \\
\hline $\mathrm{kg} \mathrm{ha}^{-1}$ & $\mathrm{Mg} \mathrm{ha}^{-1}$ & & $\mathrm{~kg} \mathrm{ha}^{-1}$ & $\mathrm{Mg} \mathrm{ha}^{-1}$ & \\
\hline 0-0-0 & 1.20 & - & 0-0-0 & 1.66 & - \\
\hline 0-29-37 & 1.27 & 1.10 & $0-20-56$ & 1.71 & 1.05 \\
\hline 45-29-37 & 1.68 & 1.49 & $22-20-56$ & 2.22 & 1.38 \\
\hline 90-29-0 & 1.81 & 1.63 & $45-20-56$ & 2.46 & 1.56 \\
\hline $90-0-37$ & 1.89 & 1.78 & $67-20-56$ & 2.73 & 1.76 \\
\hline 90-15-37 & 2.07 & 1.91 & $90-20-56$ & 2.90 & 1.89 \\
\hline 90-29-37 & 1.92 & 1.79 & $112-20-56$ & 2.87 & 1.88 \\
\hline $90-44-37$ & 1.85 & 1.68 & $67-0-56$ & 2.63 & 1.70 \\
\hline 90-29-74 & 1.95 & 1.80 & $67-10-56$ & 2.74 & 1.77 \\
\hline 134-74-0 & 1.87 & 1.74 & $67-29-56$ & 2.81 & 1.82 \\
\hline 134-29-37 & 2.05 & 1.90 & $67-40-56$ & 2.87 & 1.86 \\
\hline \multirow[t]{2}{*}{ 134-44-74 } & 2.11 & 1.98 & 67-29-0 & 2.84 & 1.84 \\
\hline & & & $112-40-56$ & 2.76 & 1.82 \\
\hline Mean & 1.81 & 1.65 & & 2.55 & 1.69 \\
\hline SED & 0.046 & 0.063 & & 0.057 & 0.047 \\
\hline CV & 20 & 23 & & 18 & 24 \\
\hline
\end{tabular}

$\dagger \mathbf{N}$, $\mathbf{P}$, and $\mathrm{K}$ applied as ammonium nitrate (34-0-0), triple superphosphate (0-46-0) and potassium chloride (0-0-60), respectively.

$\uparrow$ Response index to $\mathbf{N}$ fertilizer was determined as the ratio of $\mathbf{N}$ fertilized plots at a fixed level of $P$ and $K\left(29\right.$ and $37 \mathrm{~kg} \mathrm{ha}^{-1}$ at Stillwater, and 20 and $56 \mathrm{~kg} \mathrm{ha}^{-1}$ at Lahoma, respectively) while RI to other fertilizer treatments was calculated as the ratio of a fertilized treatment and a check (0-0-0 kg N-P-K ha ${ }^{-1}$ ). 
rated in late August to mid-September. Winter wheat has been planted in late September to early October every year.

At Stillwater between 1969 and 1995 and at Lahoma all years, the center $3.05 \mathrm{~m}$ of each plot was harvested with a conventional combine the entire $18.3-\mathrm{m}$ length for yield. The width of the net plot harvested was changed to $1.83 \mathrm{~m}$ for Exp. 222 beginning in 1996. Grain harvested from the net plot was used to determine grain yield after adjusting to a $13 \%$ moisture level. Response index to fertilization was calculated as ratio of a fertilized treatment and a check (0-0-0 kg N-P-K ha ${ }^{-1}$ ) using data from all years from respective treatments. Response index to $\mathrm{N}$ fertilizer was determined as the ratio of $\mathrm{N}$ fertilized plots at a fixed level of $\mathrm{P}$ and $\mathrm{K}$ (29 and $37 \mathrm{~kg} \mathrm{ha}^{-1}$ at Stillwater, and 20 and $56 \mathrm{~kg} \mathrm{ha}^{-1}$ at Lahoma, respectively).

\section{Weather and Soil Data}

Weather data since the inception of the two long-term experiments were obtained from the Oklahoma Mesonet (Oklahoma City, OK, www.agweather.mesonet.org/) and the corresponding research station's weather database. Daily PPT data during the months of September to August were also obtained from Oklahoma Mesonet. Mesonet measures the total amount of PPT using an unheated tipping-bucket rain gauge (R.M. Young Company, Traverse City, MI) with a 30.5 -cm-diameter opening $0.6 \mathrm{~m}$ above the ground. Similarly, $\mathrm{SM}$ at each location was calculated indirectly from the input data obtained from Oklahoma Mesonet for the years since 1997. Input data also included calibrated change in temperature or reference temperature differential $\left({ }^{\circ} \mathrm{C}\right)$ measured with a Campbell Scientific 229-L Sensor (Campbell Scientific, Inc., Logan, UT) at four depths $(5,25,60$, and $75 \mathrm{~cm})$. Using these data, the matric potential (MP in $\mathrm{kPa}$ ) was determined using the equation developed by Dingman (1994). From MP and other coefficients specific to a location supplied by Oklahoma Mesonet, the volumetric soil water content $\left(\mathrm{SM}\right.$ in $\mathrm{m}^{3} \mathrm{H}_{2} \mathrm{O}$ $\mathrm{m}^{-3}$ soil) was determined (details of equations and derivation of coefficients can be found on the Oklahoma Mesonet site (www.mesonet.org)).

The PPT was calculated for different intervals during the active growth of winter wheat for the respective sites. The intervals were September to March, September to November, February to March, and March to April. These different intervals were considered to evaluate if PPT from any of the intervals was helpful to explain variability in grain yield or RI fluctuation from year to year. In the dryland winter production system in the south central USA, the critical growing time is September to November and February to March. Over all years, PPT received between September and April averaged $45 \%$ of the total annual PPT, while only $27 \%$ was received between September and March; almost half of the total PPT was obtained during the cropping season while the other half was received after the critical crop moisture requirement passed in the month of April. Maximum and minimum temperature were used to calculate GDD and summed over the months of September to March for days where it was greater than zero. Soil moisture data obtained from Oklahoma Mesonet from September to March were used to predict trends in winter wheat grain yield and RI of fertilized plots in both experiments.

Over the years, surface soil $(0-15 \mathrm{~cm})$ samples were collected periodically $(1981,1983,1987,1995,1997$, and 1999 for Exp. 222; 1980, 1983, 1986, 1988, 1995, and 1999 for Exp. 502) immediately after winter wheat harvest using a handoperated soil probe. Each sample was a composite of 12 random cores. Soil samples were air-dried for $2 \mathrm{wk}$, ground and sieved to pass through a 2-mm screen. From each sample, N $\left(\mathrm{NH}_{4}\right.$ and $\left.\mathrm{NO}_{3}\right), \mathrm{P}, \mathrm{K}$, and soil $\mathrm{pH}$ were determined. Phosphorus and $\mathrm{K}$ were extracted and measured with Mehlich-3 extractant and analysis methods, respectively (Mehlich, 1984). Saturated paste extraction of 1:1 soil to deionized water was used for soil $\mathrm{pH}$. Ammonium $\mathrm{N}$ and $\mathrm{NO}_{3}-$ $\mathrm{N}$ were extracted using $2 \mathrm{M} \mathrm{KCl}$ (Bremner, 1965) and analyzed using a Lachat QuikChem AE automated flow injection analysis system (Lachat Instruments, Milwaukee, WI).

\section{Data Analysis}

The cumulative PPT, GDD, and SM calculated from the weather data were used individually to explore significant relationships with yield over years. Similarly, SM was used to predict RI determined at optimum $\mathrm{N}$ rate for respective sites as the ratio of grain yield of the fertilized plot (90-29-37 for Exp. 222 and 112-20-56 for Exp. 502) to that of the unfertilized plot (0-29-37 for Exp. 222 and 0-20-56 for Exp. 502). Linear combinations of fertilizer ( $\mathrm{N}-\mathrm{P}-\mathrm{K})$, cumulative GDD, cumulative PPT, and SM and their two- and three-way interactions were fitted into a full model for each experiment. A STEPWISE variable selection was employed using two selection criteria, $R^{2}$ and $C_{p}$ (Kutner et al., 2004). The significance level for entry into the model and for retention in the model was set at 0.3 and 0.1 , respectively. Once the variables were selected, models containing various numbers of predictor variables were tested for their ability to recover the variability in final grain yield based on the sums of squares each contributed. Through this process, the final model was constructed. Analysis of variance and orthogonal contrasts were used to evaluate the responsiveness to $\mathrm{N}$ application following low and high yield in the previous year in both experiments. In this study, $\mathrm{N}$ application following low and high yield in the previous year were separated based on the yield difference (previous yield high and low if the difference was positive and negative, respectively).

We further assessed if rainfall distribution coupled with previous year grain yield ( $\mathrm{Y}_{\text {previous }}$ ) level and $\mathrm{RI}_{\text {previous }}$ improved the predictability of $\mathrm{RI}_{\text {ensuing. }}$ The RI used for this analysis was determined as the ratio of $\mathrm{N}$ fertilized plots at a fixed level of $\mathrm{P}$ and $\mathrm{K}$ as shown above. Rainfall distribution during the growing season (September to April) was determined using the Shannon Diversity Index as applied to rainfall (Bronikowski and Webb, 1996).

$$
H=\frac{-\Sigma p_{i} \ln p_{i}}{\ln (8)}
$$

where $H$ denotes rainfall distribution index during the winter wheat growing season for a given year $(H=1$ and $H=0$ denote equal and lack of uniform rainfall distribution across months, respectively); $p_{i}$ is the fraction of rainfall in a given month relative to the total rainfall obtained during the growing season $(8 \mathrm{mo})$. Additionally, $\mathrm{Y}_{\text {previous}}, \mathrm{RI}_{\text {previous, }}$ and their interactions were used in multiple linear regressions to determine the combined effect of these variables in explaining the variability in the $\mathrm{RI}_{\text {ensuing }}$. To reduce multicolinearity of the interaction term, centered variables (i.e., mean subtracted from each datum) were used (Belsley et al., 1980).

Analysis of variance was used to compare the difference in soil chemical properties between the check plots and the highest N-P-K rate in each experiment (Table 2). Similarly, cultivar as source of variation in ANOVA was used to assess its contribution to the overall variation in grain yield. All 
Table 2. Surface (0-15 cm) soil chemical properties of check (no fertilizer applied) and highest rate (134-44-74 and 112-40-56 kg N-P$\mathrm{K} \mathrm{ha}^{-1}$ for Exp. 222 and 502, respectively) for selected years. $\dagger$

\begin{tabular}{|c|c|c|c|c|c|c|c|c|}
\hline \multirow[b]{2}{*}{ Year } & \multicolumn{2}{|c|}{ pH } & \multicolumn{2}{|c|}{$\mathbf{N}\left(\mathbf{N H}_{4}+\mathrm{NO}_{3}\right)$} & \multicolumn{2}{|c|}{$\mathbf{P}$} & \multicolumn{2}{|c|}{$\mathbf{K}$} \\
\hline & Check & Highest rate & Check & Highest rate & Check & Highest rate & Check & Highest rate \\
\hline & & & \multicolumn{6}{|c|}{$-\mathrm{mg} \mathrm{kg}^{-1}$} \\
\hline \multicolumn{9}{|c|}{$\underline{\text { Exp. } 222}$} \\
\hline 1981 & 5.15 & 4.95 & 14.5 & $21.5^{*}$ & 50 & $91 *$ & 346 & $403^{*}$ \\
\hline 1982 & 5.75 & $5.43 *$ & 13.0 & $21.0 *$ & 27 & $69 *$ & 345 & $385^{*}$ \\
\hline 1983 & 6.08 & $5.87 *$ & 2.0 & $\mathbf{5 . 0} *$ & 24 & $\mathbf{8 2} *$ & 360 & $412 *$ \\
\hline 1984 & 6.05 & $5.52 *$ & 3.5 & 5.3 & 30 & $89 *$ & 333 & $476^{*}$ \\
\hline 1987 & 5.68 & $5.15^{*}$ & 51.8 & 55.0 & 55 & $130 *$ & 447 & $498^{*}$ \\
\hline 1988 & 6.00 & $5.37 *$ & 27.8 & 37.0* & 24 & $195^{*}$ & 336 & $535 *$ \\
\hline 1995 & 5.93 & 5.73 & - & - & 16 & $40 *$ & 143 & $150 *$ \\
\hline 1999 & 5.92 & $5.37^{*}$ & 6.5 & 8.7 & 21 & $74 *$ & 259 & $345^{*}$ \\
\hline \multicolumn{9}{|c|}{$\underline{\text { Exp. } 502}$} \\
\hline 1980 & 5.73 & $5.28 *$ & 10.8 & 20.5 & 66 & $226 *$ & 573 & 881* \\
\hline 1983 & 5.35 & $4.83 *$ & 1.3 & 4.3 & 82 & 299* & 666 & $826^{*}$ \\
\hline 1986 & 5.58 & 5.43 & 15.3 & 3.5 & 63 & $183 *$ & 605 & $816^{*}$ \\
\hline 1988 & 4.95 & $4.73^{*}$ & 8.8 & $13.3^{*}$ & 89 & $225^{*}$ & 640 & 898* \\
\hline 1995 & 5.86 & 5.45 & 1.7 & $6.2 *$ & 51 & $129 *$ & 430 & $535^{*}$ \\
\hline 1996 & 5.53 & - & 13.9 & - & 40 & - & 416 & - \\
\hline 1999 & 5.84 & $5.28^{*}$ & 3.6 & $10.6^{*}$ & 32 & $112 *$ & 403 & $543 *$ \\
\hline
\end{tabular}

* Significant difference at $\boldsymbol{P}<\mathbf{0 . 0 5}$ between check and highest rate for each year and soil chemical property.

$\dagger$ NH4-N and NO3-N were extracted with 2 M KCl; P and $\mathrm{K}$ were extracted with Mehlich-3 extractant; pH was determined from a 1:1 soil:deionized water extractant.

statistical data analysis was performed using SAS software (SAS Institute, 2002).

\section{RESULTS AND DISCUSSION}

\section{Effect of Cultivars and N-P-K Fertilizer Response}

Cultivars were changed eight (Exp. 222) and seven (Exp. 502) times over the years in these studies. Preliminary analysis of yield among cultivars revealed no significant differences. Thus we concluded that the change of cultivar over years did contribute little to the variation in grain yield. Grain yield and RI averaged over all years are reported in Table 1.

In both experiments, response to low and medium $\mathrm{N}-$ $\mathrm{P}-\mathrm{K}$ treatments did not begin to show significance until the eighth year of the studies (data not shown). The only apparent difference in grain yield was between plots receiving high rates of $\mathrm{N}-\mathrm{P}-\mathrm{K}$ and the check plots with no $\mathrm{N}$ and no $\mathrm{N}-\mathrm{P}-\mathrm{K}$. This suggests that during the first $8 \mathrm{yr}$, the nutrient supplying capacity of the soils was similar to the $\mathrm{N}, \mathrm{P}$, and $\mathrm{K}$ supplying capacity of the low and intermediate fertilizer rates. In a long-term cotton (Gossypium hirsutum L.) N-P-K fertilizer response study, Girma et al. (2007b) found similar results. Since 1978, however, significant differences between N-P-K treatments were observed. A decrease in organic matter might be the cause of this response. Data from a 114-yr experiment in Oklahoma showed that organic matter decreased annually at a rate of $0.02 \%$ in the check plot that received no fertilizer (Girma et al., 2007a).

\section{Cumulative GDD, PPT, and SM as Predictors of Grain Yield and RI}

Variability in winter wheat grain yield or RI over years was not related $(P>0.1)$ well to cumulative GDD or cumulative PPT fitted separately (data not shown). In both experiments, the coefficient of simple determina- tion was $<5 \%$ with $>95 \%$ of the variability unexplained. This is consistent with findings from Lobell et al. (2004) who noted that weather variability was two to three times less than soil variability in Mexico.

Soil moisture at the depth of $75 \mathrm{~cm}$ was significantly related to both grain yield $\left(R^{2}=0.36, P<0.05\right)$ and RI $\left(R^{2}=0.59, P<0.01\right)$ in Exp. 222 (Fig. 1 and 2). For Exp. 502, only grain yield showed a significant relationship $\left(R^{2}=0.29, P<0.1\right)$ with $\mathrm{SM}$ at the $60-\mathrm{cm}$ depth (Fig. 3). Maximum grain yield and RI were achieved at $\mathrm{SM}$ of $0.43 \mathrm{~m}^{3} \mathrm{H}_{2} \mathrm{O} \mathrm{m} \mathrm{m}^{-3}$ soil at Stillwater. At Lahoma, maximum yields were achieved at the SM level of $0.39 \mathrm{~m}^{3} \mathrm{H}_{2} \mathrm{O} \mathrm{m}^{-3}$ soil. It has been reported that $\mathrm{SM}$ levels beyond optimal level can induce foliar and root diseases that can affect yield and response to fertilizer in wheat (Ma et al., 2004). In corn, research showed that including meteorological data for yield prediction models improved fertilizer management decisions (Bundy and Andraski, 1995; Derby et al., 2004, 2005). Although significant, the variability explained by SM

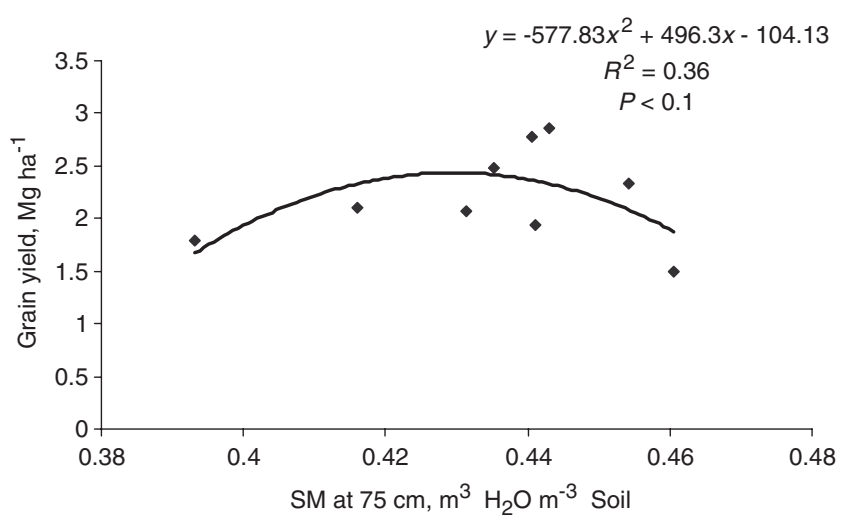

Fig. 1. Soil moisture (SM) as a predictor of grain yield in Exp. 222 at Stillwater, OK, for data compiled from 9 yr (1997-2005). 


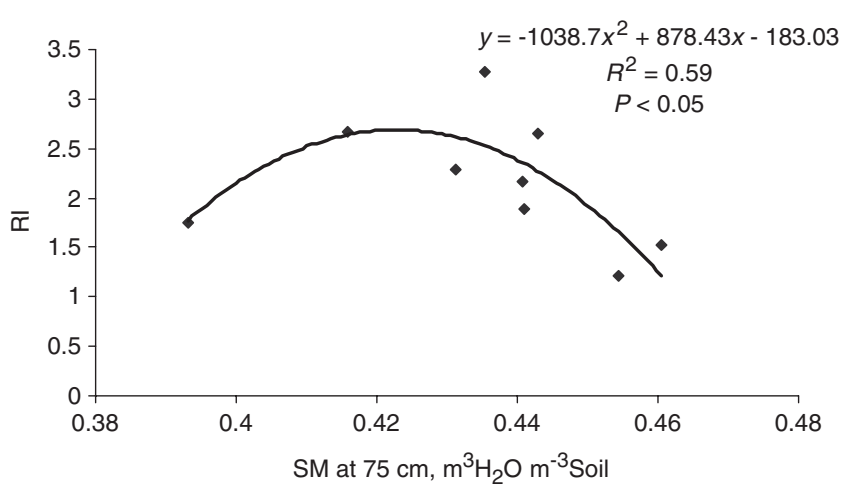

Fig. 2. Soil moisture (SM) as a predictor of response index (RI) in Exp. 222 at Stillwater, OK, for data compiled from 9 yr (1997-2005).

was $<60 \%$ leaving $40 \%$ of the variability unexplained. This shows that other factors other than GDD, PPT, or $\mathrm{SM}$ may modify $\mathrm{N}$ response in a given year. Among these, soil $\mathrm{pH}$ might have been important, since soil $\mathrm{pH}$ decreased with the application of high rates of $\mathrm{N}$ in both experiments (Table 2).

Simple models may not be able to explain as much variability under a wide set of environmental conditions, but their application and parameterization is far less demanding. Using the STEPWISE selection in SAS (SAS Institute, 2002), components exhibiting the least contribution to the regression sum of squares and being nonsignificant individually $(P>0.1)$ were discarded and a new reduced model was fitted for each of the two experiments for grain yield only (Table 3). The total variability explained by the reduced model was 72 and 64\% for Exp. 222 and 502, respectively. Although the selection procedure produced four and three terms as components that contribute $>1 \%$ variability in the reduced model, for Exp. 222 and 502, respectively, only one term in each case was responsible for explaining most of the variability due to the model and the other terms contributed $<8 \%$. For Exp. 222, fertilizer $\times \mathrm{SM}$ explained $59 \%$ of variability in grain yields while in Exp. 502 fertilizer alone explained $52 \%$ of the variability in grain yield. Fertilizer $\times$ cumulative GDD interaction explained 7\% variability in Exp. 222 while cumulative PPT explained 7\% variability in Exp. 502. At Stillwater,

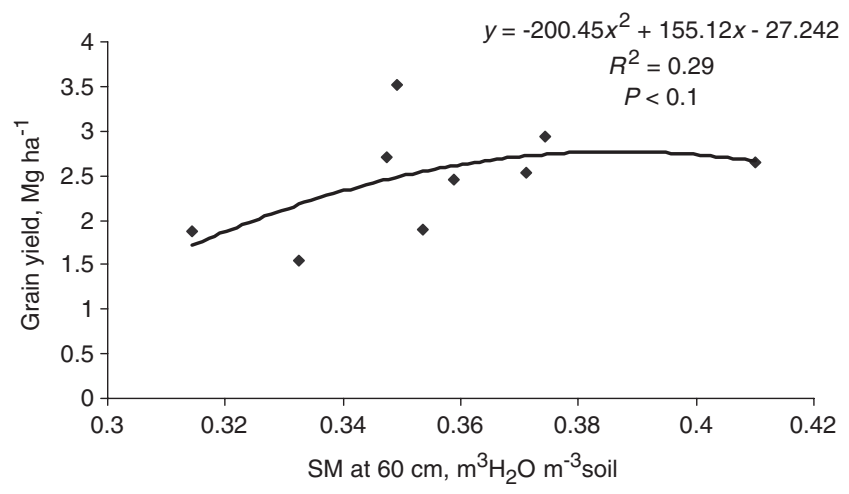

Fig. 3. Soil moisture (SM) as a predictor of grain yield in Exp. 502 at Lahoma, OK, for data compiled from 9 yr (1997-2005).
Table 3. Parameter estimates, probabilities, and partial squared correlation coefficients for variables used to predict winter wheat grain yield at Stillwater (Exp. 222) and Lahoma (Exp. 502), OK.

\begin{tabular}{lccc}
\hline & Estimate & Partial $\boldsymbol{R}^{\mathbf{2}} \dagger$ & $\boldsymbol{P}$ \\
\hline & Exp. 222 & & \\
Intercept & $-\mathbf{3 . 9 6}$ & - & $* * *$ \\
Fertilizer $\times$ soil moisture & $\mathbf{0 . 0 2 5}$ & $\mathbf{0 . 5 9}$ & $* * *$ \\
Fertilizer $\times$ cumulative GDD & $\mathbf{0 . 0 0}$ & $\mathbf{0 . 0 7}$ & ns \\
Soil moisture & $\mathbf{0 . 0 9 2}$ & $\mathbf{0 . 0 3}$ & ns \\
Cumulative PPT & $-\mathbf{0 . 0 1 1}$ & $\mathbf{0 . 0 3}$ & ns \\
Cumulative GDD & $\mathbf{0 . 0 0}$ & $\mathbf{0 . 0 1}$ & ns \\
& $\mathbf{E x p . 5 0 2}$ & & \\
Intercept & $\mathbf{3 . 8 9}$ & - & $* * *$ \\
Fertilizer & $\mathbf{1 . 4 2 0 0}$ & $\mathbf{0 . 5 2}$ & $* * *$ \\
Cumulative PPT & $-\mathbf{0 . 0 2 5 0}$ & $\mathbf{0 . 0 7}$ & ns \\
Cumulative GDD & $-\mathbf{0 . 0 0 1 0}$ & $\mathbf{0 . 0 5}$ & ns \\
\hline
\end{tabular}

*** Significant at the 0.001 level.

$\dagger$ the squared partial correlation coefficients calculated using Type III partial sum of squares.

† ns, not significant.

the fertilizer $\times$ SM interaction explained the yield variability better than the individual variables, while most of the variability at Lahoma was a function of fertilizer alone. The amount of crop yield variability explained by models is mixed (Lobell et al., 2004; 2005; Ma et al., 2004).

\section{Responsiveness to N Application Following Low and High Yielding Years}

At Stillwater, the highest RI was obtained with the highest rate of $\mathrm{N}-\mathrm{P}-\mathrm{K}\left(134-44-75 \mathrm{~kg} \mathrm{ha}^{-1}\right)$. The lowest was obtained with 0-29-37 indicating response to fertilizer is a function of $\mathrm{N}$ supply in the presence or absence of $\mathrm{P}$ and $\mathrm{K}$ fertilizers. At Lahoma, RI was a function of only $\mathrm{N}$ where it was low with no $\mathrm{N}$ or lower rates of $\mathrm{N}$. Apparently each site has an inherent fertility capacity that influences the fertilizer requirement of each field.

Comparison of $\mathrm{N}$ responsiveness following low and high yield in the previous year in both experiments showed that the yield level in the previous year had a significant effect on the $\mathrm{N}$ fertilizer responsiveness of the ensuing year. For all years (44\% of the years experiments were conducted) where the previous year's yields were low, the following year had a low RI. Conversely, in years where the previous year's yield was high, the ensuing year had a high RI in both experiments. When yields were low the previous year, RI values peaked at a low $\mathrm{N}$ rate $\left(45 \mathrm{~kg} \mathrm{~N}^{-1}\right.$ at Stillwater and Lahoma, Fig. 4). Alternatively, the $90 \mathrm{~kg} \mathrm{~N}^{-1}$ achieved a high RI when the previous year's yields were high at both locations (Fig. 4). This suggests that the amount of $\mathrm{N}$ harvested in grain the previous year has a significant effect on the RI of the ensuing year. Poor yield levels in the previous year are associated with poor $\mathrm{N}$ use efficiency and there is a chance that unused $\mathrm{N}$ can be used the following season. This would in turn reduce the RI of the ensuing season when $\mathrm{N}$ is applied. It is important to note that low previous year yields could be attributed to several factors. In these dryland winter wheat production systems we suspect that low yields 
(a)

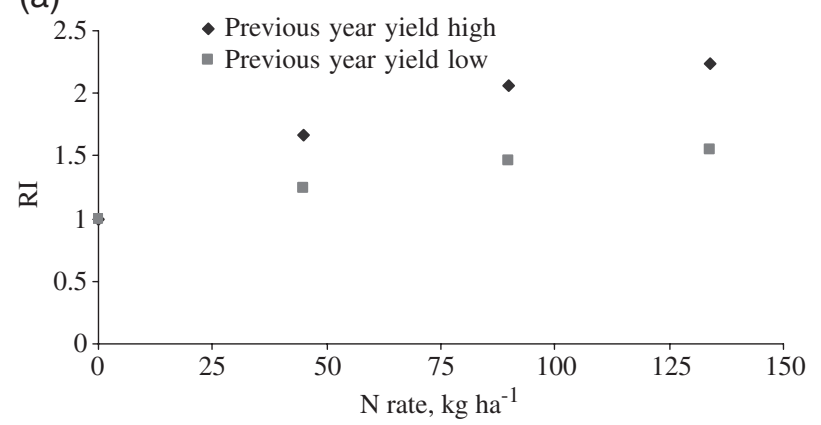

(b)

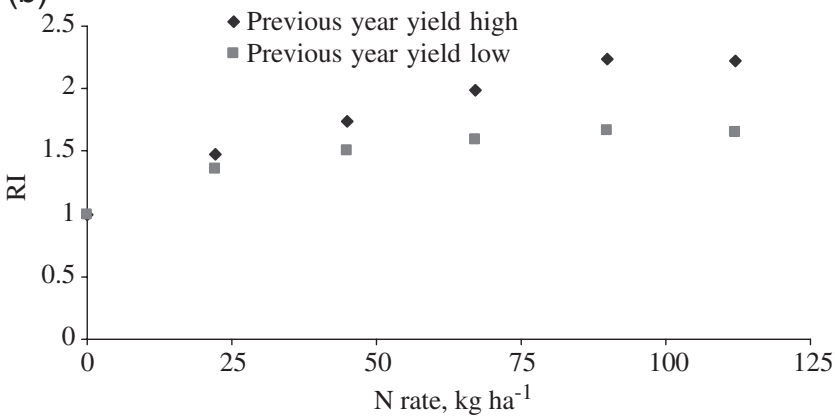

Fig. 4. Comparison of $\mathrm{N}$ responsiveness (RI) of the ensuing year when yields were low and high the previous year in Exp. 222 (top) and Exp. 502 (bottom).

are associated with moisture availability at the peak crop demand. Consequently, if fertilizer is pre-plant incorporated into the soil and not used by the crop, the chances of recovering this in the coming season is high. If moisture and growing conditions are not limiting and yield is improved, RI will be high in the subsequent year. According to Camara et al. (2003), when precipitation is below normal, yield tended to remain flat after $45 \mathrm{~kg}$ $\mathrm{N} \mathrm{ha}^{-1}$ (based on $\mathrm{N}$ levels ranging form $0-135 \mathrm{~kg} \mathrm{ha}^{-1}$ ) while yield was increased up to $90 \mathrm{~kg} \mathrm{ha}^{-1}$ rate and leveled off when precipitation level was above average ( $\approx 400 \mathrm{~mm}$ between October and June).

The index (I) computed as Eq. [2] was a good predictor of current year RI at both Stillwater and Lahoma $\left(R^{2}=0.52\right.$ and 0.42 , respectively $)$.

$$
I=0.24 \quad \mathrm{Y}_{\text {previous }} \times \mathrm{RI}_{\text {previous }} \times H
$$

The exponential relationship between the index ( $x$ axis) and current year RI $(Y)$ is given in Fig. 5. The only limitation of this relationship is the lack of data to observe what will happen for larger values of $x$ as yield levels increase. This might not be a very critical limitation for dryland wheat as yield potential is limited mostly by moisture availability. The practical significance of this relationship is that producers can adjust preplant or topdress $\mathrm{N}$ fertilizer rates using this relationship as a decision aid.

The inclusion of $\mathrm{Y}_{\text {previous }}$ and $\mathrm{RI}_{\text {previous }}$ as predictor variables in a multiple linear regression without the evenness factor explained 49 and $28 \%$ of the variability in ensuing year RI at Stillwater and Lahoma, respectively. Addition of an interaction term explained 9

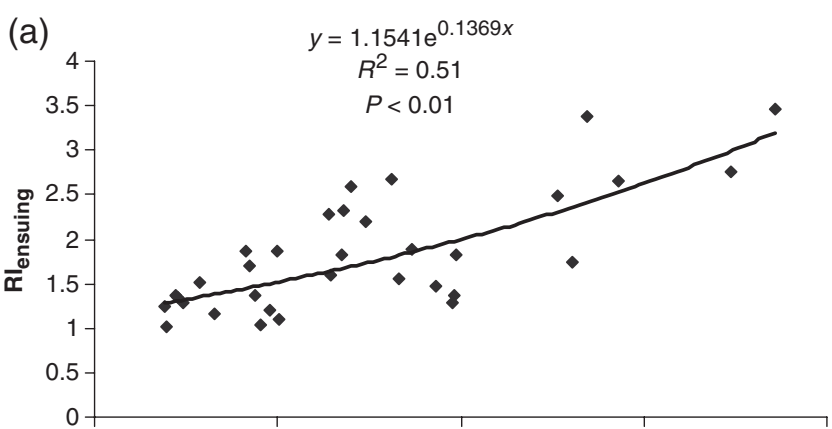

(b)

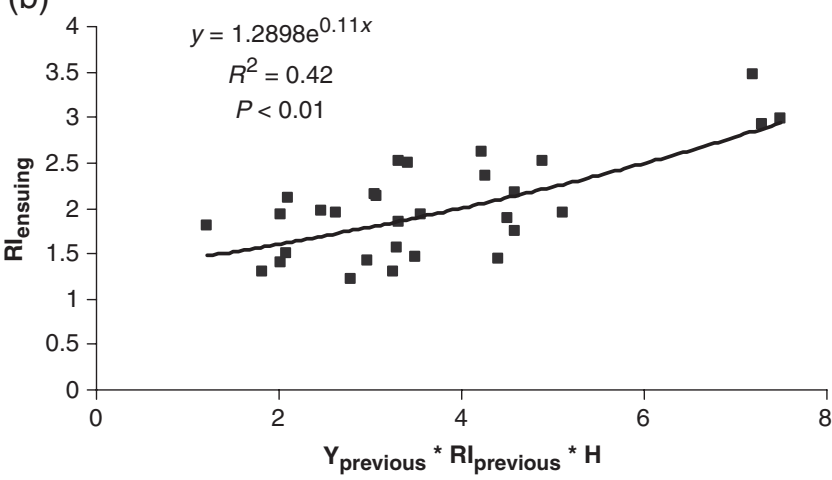

Fig. 5. Relationship between an index developed from previous year grain yield ( $\left.\mathbf{Y}_{\text {previous }}\right)$, previous year response index ( $\left.R I_{\text {previous }}\right)$, and rainfall distribution $(H)$ versus ensuing year $R I$ ( $R I_{\text {ensuing }}$ ) for Exp. 222 (top) and Exp. 502 (bottom) at Stillwater and Lahoma, $\mathrm{OK}$, respectively, for data compiled over more than $30 \mathrm{yr}$.

and $10 \%$ additional variability in ensuing year RI for Exp. 222 and 502, respectively Table 4). Inclusion of $H$ in this multiple linear regression explained $2 \%$ additional variability only (data not shown), thus was removed from the multiple linear regression model. The multiple linear regression for Exp. 222 is

$$
\begin{aligned}
\mathrm{RI}_{\text {ensuing }}= & 0.24-0.29 \times \mathrm{RI}_{\text {previous }}+0.58 \times \mathrm{Y}_{\text {previous }} \\
& +0.32 \times \mathrm{RI}_{\text {previous }} \times \mathrm{Y}_{\text {previous }}
\end{aligned}
$$

and for 502 is

$$
\begin{aligned}
\mathrm{RI}_{\text {ensuing }}= & -0.83+0.65 \times \mathrm{RI}_{\text {previous }}+1.08 \times \mathrm{Y}_{\text {previous }} \\
& +0.63 \times \mathrm{RI}_{\text {previous }} \times \mathrm{Y}_{\text {previous }}
\end{aligned}
$$

where $\mathrm{RI}_{\text {previous }}$ and $\mathrm{Y}_{\text {previous }}$ are as defined above; $\mathrm{RI}_{\text {ensuing }}$ denotes the ensuing year RI.

Obviously, the inclusion of the two predictor variables and their interaction in a model captured the maximum possible variability in the predicted ensuing year RI. The positive coefficients show the direct relation between the predictor and predicted variables. The same explanation discussed above, that is, high yield in the previous year due to optimum growing conditions is likely to take up applied $\mathrm{N}$ fertilizer, increases the RI to applied fertilizer for that year. It follows logically that the ensuing year RI would be higher while the opposite occurs if yield level was low and RI was poor the previous year. Although the equation structures for Eq. [3] and Eq. [4] are similar, the constants and coefficients are different for each site. Producers are 
Table 4. Simple and multiple regression coefficient estimates for regressing previous year yield ( $\mathbf{Y}_{\text {previous}}$ ), previous year $\mathbf{R I}\left(\mathbf{R} \mathbf{I}_{\text {previous}}\right)$, and interaction of the two against ensuing year RI at Stillwater (Exp. 222) and Lahoma (Exp. 502), OK.

\begin{tabular}{|c|c|c|c|c|c|c|}
\hline \multirow[b]{2}{*}{ Exp. } & \multirow[b]{2}{*}{ Model } & \multicolumn{4}{|c|}{ Coefficient estimate } & \multirow[b]{2}{*}{$R^{2}$} \\
\hline & & Intercept & $\mathbf{Y}_{\text {previous }}$ & $\mathbf{R I}_{\text {previous }}$ & Interaction & \\
\hline 222 & Only $\mathbf{Y}_{\text {previous }}$ & 1.18 & $0.35 *$ & - & - & $0.15 *$ \\
\hline 222 & Only RI previous & 0.86 & - & $\mathbf{0 . 5 3} * * *$ & - & $0.36 * * *$ \\
\hline 222 & $\mathbf{Y}_{\text {previous }}+\mathbf{R I}$ previous & 0.30 & $0.32 * *$ & $0.51 * * *$ & - & $0.49 * * *$ \\
\hline 222 & $\mathbf{Y}_{\text {previous }}+\mathbf{R I}$ previous + Interaction & 0.24 & $0.29 * *$ & $\mathbf{0 . 5 8} * * *$ & $0.32 * *$ & $0.58 * * *$ \\
\hline 502 & Only Y Yrevious & 2.22 & $-0.13 \mathrm{~ns} \dagger$ & - & - & $0.01 \mathrm{~ns}$ \\
\hline 502 & Only RI previous & 1.15 & - & $0.51 * *$ & - & $0.20 * *$ \\
\hline 502 & $\mathbf{Y}_{\text {previous }}+\mathbf{R} \mathbf{I}_{\text {previous }}$ & -0.20 & $0.45^{*}$ & $0.85 * * *$ & - & $0.29 * *$ \\
\hline 502 & $\mathbf{Y}_{\text {previous }}+\mathbf{R I} \mathbf{I}_{\text {previous }}+$ Interaction & -0.83 & $0.65 * *$ & $1.08 * * *$ & $0.63 *$ & $\mathbf{0 . 3 8} * * *$ \\
\hline
\end{tabular}

* Significant at the 0.05 level.

** Significant at the 0.01 level.

*** Significant at the 0.001 level.

$\dagger$ ns, not significant at $P<0.05$. Probabilities test the null hypothesis that a coefficient has " 0 " value while the significance shown in the $\boldsymbol{R}^{2}$ column refers to the model significance test.

advised to collect yield data and examine relationships on their own farms to fine tune this approach as a decision aid for their soils.

\section{REFERENCES}

Asseng, S., P.D. Jamieson, B. Kimball, P. Pinter, K. Sayre, J.W. Bowden, and S.M. Howden. 2004. Simulated wheat growth affected by rising temperature, increased water deficit and elevated atmospheric $\mathrm{CO}_{2}$. Field Crops Res. 85:85-102.

Belsley, D.A., E. Kuh, and R.E. Welsch. 1980. Regression diagnostics. John Wiley \& Sons, Inc, New York.

Black, A.L., and A. Bauer. 1988. Setting winter wheat yield goals. p. 24-34. In J.L. Havlin (ed.) Proc. Workshop Central Great Plains Profitable Wheat Management, Wichita, KS. 17-20 Aug. 1988. Potash and Phosphate Inst., Atlanta, GA.

Blackmer, A.M., R.D. Voss, and A.P. Mallarino. 1997. Nitrogen fertilizer recommendations for corn in Iowa. Iowa State Univ. Ext. Publ. Pm-1714. Iowa State Univ. Ext., Ames.

Bremner, J.M. 1965. Inorganic forms of nitrogen. In C.A. Black et al. (ed.) Methods of soil analysis, Part 2. Agronomy 9:1179-1237. Am. Soc. of Agron., Madison WI.

Bonhomme, R. 2000. Bases and limits to using 'degree days' units. Eur. J. Agron. 13:1-10.

Bronikowski, A.M., and C. Webb. 1996. A critical examination of rainfall variability measures used in behavioral ecology studies. Behav. Ecol. Sociobiol. 39:27-30.

Bundy, L.G., and T.W. Andraski. 1995. Soil yield potential effects on performance of soil nitrate tests. J. Prod. Agric. 8:561-568.

Camara, K.M., W.A. Payne, and P.E. Rasmussen. 2003. Long-term effects of tillage, nitrogen, and rainfall on winter wheat yields in the Pacific Northwest. Agron. J. 95:828-835.

Challinor, A.J., T.R. Wheeler, P.Q. Craufurd, and J.M. Slingo. 2005. Simulation of the impact of high temperature stress on annual crop yields. Agric. For. Meteorol. 135:180-189.

Chang, J.M., D.E. Clay, C.G. Carlson, C.L. Reese, S.A. Clay, and M.M. Ellsbury. 2004. Defining yield goals and management zones to minimize yield and nitrogen and phosphorus fertilizer recommendation errors. Agron. J. 96:825-831.

Dahnke, W.C., L.J. Swenson, R.J. Goos, and A.G. Leholm. 1988. Choosing a crop yield goal. SF-822. North Dakota State Ext. Serv., Fargo, ND.

Derby, N.E., F.X.M. Casey, R.E. Knighton, and D.D. Steele. 2004. Midseason nitrogen fertility management for corn based on weather and yield prediction. Agron. J. 96:494-501.

Derby, N.E., D.D. Steele, J. Terpstra, R.E. Knighton, and F.X.M. Casey. 2005. Interactions of nitrogen, weather, soil, and irrigation on corn yield. Agron. J. 97:1342-1351.

Dingman, S.L. 1994. Physical hydrology. Prentice Hall, Upper Saddle River, NJ.

El-Harris, M.K., V.L. Cochran, L.F. Elliott, and D.F. Bezdicek. 1983. Effect of tillage, cropping, and fertilizer management on soil nitrogen mineralization potential. Soil Sci. Soc. Am. J. 47:1157-1161.
Flowers, M., R. Weiz, R. Heininger, D. Osmond, and C. Crozier. 2004 In-season optimization and site-specific nitrogen management for soft red winter wheat. Agron. J. 96:124-134.

Girma, K., S.L. Holtz, D.B. Arnall, B.S. Tubaña, and W.R. Raun. 2007a. The Magruder plots: Untangling the puzzle. Agron. J. 99: 1191-1198.

Girma, K., R.K. Teal, K.W. Freeman, B. Tubana, S. Holtz, R.K. Boman, and W.R. Raun. 2007b. Cotton lint yield and quality as affected by applications of N, P and K fertilizers. J. Cotton Sci. 11: $12-19$.

Janzen, R.R. 1987. Effect of fertilizer on soil productivity in long-term wheat rotations. Can. J. Soil Sci. 67:165-174.

Jenkinson, D.S. 1991. The Rothamsted long-term experiments: Are they still of use? Agron. J. 83:2-10.

Johnson, G.V., and W.R. Raun. 2003. Nitrogen response index as a guide to fertilizer management. J. Plant Nutr. 26:249-262.

Johnson, G.V., W.R. Raun, and R.W. Mullen. 2000. Nitrogen use efficiency as influenced by crop response index. p. 291. In Agronomy abstracts. ASA, CSSA, and SSSA, Madison, WI.

Kutner, M.H., C.J. Nachtsheim, and J. Neter. 2004. Applied linear regression models. 4th ed. McGraw-Hill Comp., Inc., New York. p. 294-305.

Lobell, D.B., J.I. Ortiz-Monasterio, and G.P. Anser. 2004. Relative importance of soil and climate variability for nitrogen management in irrigated wheat. Field Crops Res. 87:155-165.

Lobell, D.B., J.I. Ortiz-Monasterio, G.P. Anser, R.L. Naylor, and W.P. Falcon. 2005. Combining field surveys, remote sensing, and regression trees to understand yield variations in an irrigated wheat landscape. Agron. J. 97:241-249.

Lu, H., C. Lu, L. Chan, and M. Wei. 2001. Seasonal variation in linear increase of taro harvest index explained by growing degree days. Agron. J. 93:1136-1141.

Ludwig, F., and S. Asseng. 2006. Climate change impacts on wheat production in a Mediterranean environment in Western Australia. Agri. Syst. 90:159-179.

Ma, B.L., W. Yan, L.M. Dwyer, J. Frégeau-Reid, H.D. Voldeng, Y. Dion, and H. Nass. 2004. Graphic analysis of genotype, environment, nitrogen fertilizer, and their interactions on spring wheat yield. Agron. J. 96:169-180.

McMaster, G.S., and W.W. Wilhelm. 1997. Growing degree-days: One equation, two interpretations. Agric. For. Meteorol. 87:291-300.

Mehlich, A. 1984. Mehlich 3 soil test extractant: A modification of Mehlich 2 extractant. Commun. Soil Sci. Plant Anal. 15: $1409-1416$.

Motavalli, P.P., L.G. Bundy, W.W. Andraski, and A.E. Peterson. 1992. Residual effects of long-term nitrogen fertilization on nitrogen availability to corn. J. Prod. Agric. 5:363-368.

Mullen, R.W., K.W. Freeman, W.R. Raun, G.V. Johnson, M.L. Stone, and J.B. Solie. 2003. Identifying an in-season response index and the potential to increase wheat yield with nitrogen. Agron. J. 95:347-351.

Odell, R.T., W.M. Walker, L.V. Boone, and M.G. Oldham. 1983. The Morrow plots: A century of learning. Illinois Agric. Exp. Stn. Bull. 775, Urbana, IL. 
Peng, S., J. Huang, J.E. Sheehy, R.C. Laza, R.M. Visperas, X. Zhong, G.S. Centeno, G.S. Khush, and K.G. Cassman. 2004. Rice yields decline with higher night temperature from global warming. Proc. Natl. Acad. Sci. USA 101:9971-9975.

Phillips, D.L., J.J. Lee, and R.F. Dodson. 1996. Sensitivity of the US Corn Belt to climate change and elevated $\mathrm{CO}_{2}$ : I. Corn and soybean yields. Agric. Syst. 52:481-502.

Raun, W.R., J.B. Solie, M.L. Stone, D.L. Zavodny, K.L. Martin, and K.W. Freeman. 2005. Automated calibration stamp techno- logy for improved in-season nitrogen fertilization. Agron. J. 97: 338-342.

SAS Institute. 2002. The SAS system for Windows. Version 8.0. SAS Inst., Cary, NC.

Sayre, K.D., S. Rajaram, and R.A. Fischer. 1997. Yield potential progress in short bread wheats in Northwest Mexico. Crop Sci. 37:36-42.

Turner, N.C. 1997. Further progress in crop water relations. Agron. J. 58:293-338. 